\title{
MOLECULAR INTERACTION OF RICIN-A WITH CASPASE-3, CASPASE-8, CASPASE-9 AND AUTOPHAGY-RELATED GENE5 (ATG5) TO UNDERSTAND ITS ROLE AS ANTICANCER AGENT
}

\author{
I. E. Herawati ${ }^{1,2}$, R. Lesmana ${ }^{3,4}$, J. Levita ${ }^{1, \bowtie}$ and A. Subarnas ${ }^{1}$ \\ ${ }^{1}$ Department of Pharmacology and Clinical Pharmacy, Universitas Padjadjaran, \\ Sumedang-45363, West Java, Indonesia \\ ${ }^{2}$ Department of Pharmacy, Universitas Al Ghifari, Bandung-40293, West Java, Indonesia \\ ${ }^{3}$ Physiology Molecular Laboratory, Universitas Padjadjaran, \\ Sumedang-45363, West Java, Indonesia \\ ${ }^{4}$ Department of Medical Basic Sciences, Universitas Padjadjaran, \\ Sumedang-45363, West Java, Indonesia \\ ${ }^{\square}$ Corresponding Author: jutti.levita@unpad.ac.id
}

\begin{abstract}
The stimulation of caspases, i.e. intracellular cysteine proteases which cleave their substrates at aspartic acid residues, can lead to apoptosis. Autophagy, the regulated cellular degradation, is commenced from the engulfment of unwanted cytoplasmic content, followed by the fusion with the lysosome, and the degradation. Ricin contained in the seeds of Ricinus communis L. is a type II ribosome-inactivating protein that possesses cytotoxicity activity against various cancer cell lines. Our work investigated the structure-based molecular interaction of caspase-3, -8, -9, and autophagyrelated gene5 (ATG5) with ricin-A. The X-ray crystal structures of human caspase-3, -8, -9, and ATG5 were retrieved from https:/www.rcsb.org/structure/. The protein-protein docking was performed by employing ClusPro (https://cluspro.org/). The results indicated that ricin-A reveals similar binding modes in terms of the hydrogen bond (Ser205, Arg207, Ser209) and hydrophobic interaction (Trp206 and Phe256) with those of Ac-DEVD-AFC (a caspase3 substrate). Ricin-A interacts with Arg413 and Ser411 that were located antiparallel in the binding pocket of caspase8. A part of ricin-A also binds to Val410, a residue located in pocket S2 of caspase-8. Moreover, ricin-A interacts with several amino acid residues in caspase-9, thus activation of caspase-9 by ricin-A occurs on an allosteric site. Several hydrogen bonds are built between ricin-A and residues 395-479 in ATG5. In conclusion, ricin-A might be able to induce the downstream executioner caspases, particularly caspase-3, -8, -9, and modulates ATG5, thus activates apoptosis and inhibits autophagy.
\end{abstract}

Keywords: Apoptosis, Autophagy, Caspase, Ricin-A, Ricinus communis L.

RASĀYAN J. Chem., Vol. 14, No.3, 2021

\section{INTRODUCTION}

Apoptosis (Greek: to fall away from), both intrinsic and extrinsic, is caused by the activation. ${ }^{1,2,3}$ Caspases, a family of dimeric cysteine proteases, could selectively recognize their substrates. The specific tetrapeptide sequences, which are distinguished by Asp residue at the P1 (C-terminus) and P4 (N-terminus) of caspase3 , refer to its selectivity. The substrate of caspase-3 is Ac-DEVD-AFC, whereas caspase-1, $-4,-7$ and -8 show activity for DEVD (sequence Ac-Asp-Glu-Val-Asp-7-Amino-4-methyl coumarin) substrate. ${ }^{3,4}$

The specific active site cysteine-histidine dyads (His-144/Cys-186) in L3 and L4 is used for human caspases. $^{5}$

Autophagy is an evolutionary retained catabolic mechanism involved in cellular homeostasis and stress reactions, including by lysosomal pathways the degradation of target proteins or organelles. There are three forms of autophagy, namely, ${ }^{6}$ macroautophagy, microautophagy, and autophagy chaperone-mediated by a chaperone, which is characterized by different mechanisms of delivering cargoes to the lysosome. ${ }^{7}$ The 
autophagic mechanism is regulated by the autophagy-related genes (ATG). To improve the impact of cancer therapy and address the emerging issue of drug resistance, innovative therapeutic strategies are needed. Theoretically, autophagic induction of death, type II programmed cell death, may be useful in apoptosisresistant cancer cells and complement several apoptosis treatments approaches in cancer cells. ${ }^{8}$

Ricin isolated from the seeds of Ricinus communis L. is a heterodimeric two-domain polypeptide protein that comprises an enzymatically active domain (namely ricin-A or rRNA N-glycosidase, is depicted in Fig.1) and a lectin-like domain (chain B). ${ }^{9}$ The single-chain $\mathrm{A}$ is capable to inactivate over 1500 ribosomes/minute. ${ }^{10}$ Ricin could induce apoptosis and autophagy. ${ }^{11}$ It has been reported that a single molecule of ricin in the cytosol has been widely explored for its anticancer activity, e.g. in HeLa cells (IC ${ }_{50}$ for cell viability $=1 \mu \mathrm{g} / \mathrm{mL}) .{ }^{12}$ Ricin can induce activation of the caspase in immortalized epithelial cell lines (MAC-T), ${ }^{13}$ moreover, in ricin-treated Vero cell lines, the cellular protein synthesis levels were decreased by $\geq 60 \%$ at 8 hours. ${ }^{14}$

We considered that it would be important to understand the mechanism of ricin-A in inhibiting the growth of cancer cell lines, therefore, in this paper, we report a structure-based study of the molecular interaction of ricin-A with the caspases and ATG5.

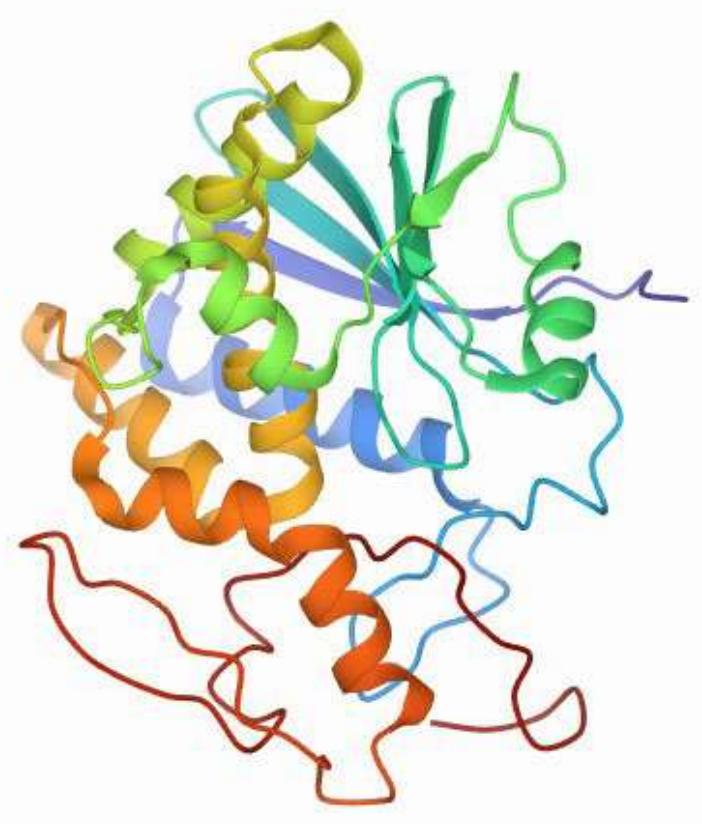

Fig.-1: 3D Molecular Structure of Ricin-A, a hydrolase protein isolated from Ricinus communis (DOI: http://doi.org/10.2210/pdb2AAI/pdb), deposited in https://www.rcsb.org/ (PDB code 2AAI). ${ }^{15}$

\section{Hardware}

\section{EXPERIMENTAL}

The hardware used was Asus X555U (15-inch, Mid 2018) embedded with Microsoft windows 10 Intel Core i5 6200u processor and 12 GB NVidia gforce $920 \mathrm{~m}$.

\section{Preparation of Protein Structures}

The X-ray crystal structures of protein ricin (PDB ID 2AAI; DOI: 10.2210/pdb2AAI/pdb), human caspase3 (PDB ID 2C1E; DOI:10.2210/pdb2C1E/pdb) caspase-8 (PDB ID 3KJQ; DOI: 10.2210/pdb3KJQ/pdb), caspase-9 (PDB ID 2AR9; DOI:10.2210/pdb2AR9/pdb), ATG5 (PDB ID 4TQ1; DOI: 10.2210/pdb4TQ1/pdb) (Fig.-2) were downloaded from the Research Collaboratory for Structural Bioinformatics (RCSB) protein data bank (available online: https://www. rcsb.org/structure/). The protein structures were prepared by following Megantara and colleagues (2021). ${ }^{16}$ 


\section{Protein-Protein Docking}

The protein-protein docking was performed by employing ClusPro (https://cluspro.org/), which requires two files of proteins in PDB format. ${ }^{17}$ This software selects one of the 10 models closest to the native structure, each represented by the center of a highly populated cluster of low-energy conformations. The balanced-set of energy coefficient was chosen because it works generally well for enzyme-inhibitor complexes. ${ }^{18}$

\section{RESULTS AND DISCUSSION}

In this work, we studied the molecular interaction of ricin-A with caspase-3, $-8,-9$, and ATG5 to understand its role as an anticancer agent.

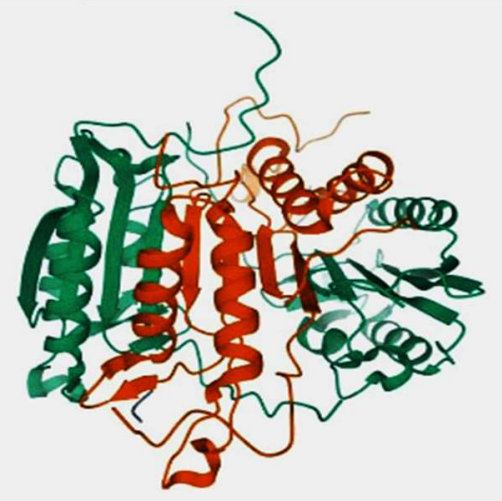

d.

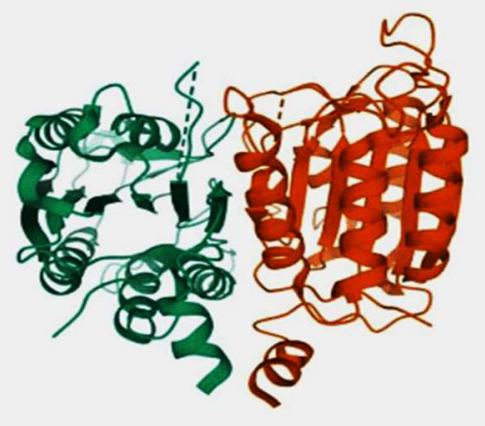

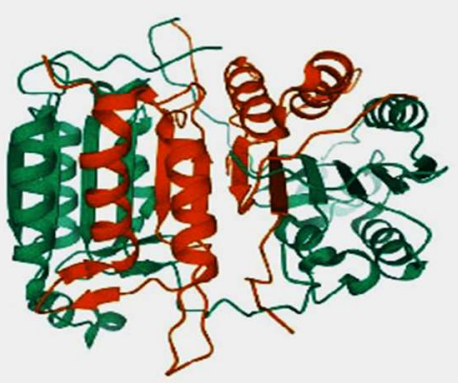

d.

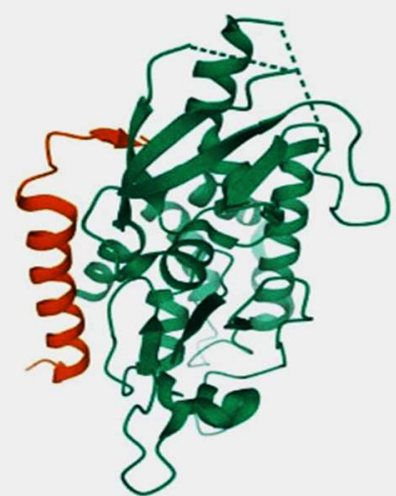

Fig.-2: 3D Molecular Structure of (a) Human Caspase-3 (PDB ID 2C1E; DOI:10.2210/pdb2C1E/pdb); (b) Caspase8 (PDB ID 3KJQ; DOI: 10.2210/pdb3KJQ/pdb); (c) ATG5 (PDB ID 4TQ1; DOI: 10.2210/pdb4TQ1/pdb); (d)

Caspase-9 (PDB ID 2AR9; DOI:10.2210/pdb2AR9/pdb)

The binding mode and affinity of ricin-A in caspase-3, -8, -9, and ATG5 are presented in Table-1. In a previous study by Megantara et al., (2020), Ac-DEVD-AFC, a caspase-3 substrate-built hydrogen bonds with Arg64, Gln161, Arg207, Ser205, Ser209, and hydrophobic interactions to Phe256, Trp206, Trp214. ${ }^{3}$ Docking results between ricin-A and caspase-3 revealed the formation of hydrogen bonds at residue Ser205, Arg207, and Ser209. Moreover, hydrophobic interactions were observed with Trp206 and Phe256. Thus, ricin-A is predicted could interact with the executioner caspase- 3 in the same location where the substrate (Ac-DEVD-AFC) binds.

In caspase-8, the inhibitor's mainchain is antiparallel concerning residues lining the binding pocket (residues 411-413), similar to other proteases. The carboxylic group of aspartate residues and hydrogen bonds with Gln358 formed salt bridges with Arg413 and Arg260. Apart from the salt bridges, Arg413 is an important residue connecting the mainchain and the peptide inhibitor chain. ${ }^{19}$

Nonetheless, the docking of ricin-A and caspase- 8 showed that there were hydrogen bonds formed with Arg413 and Ser411 which was following the position of the residue that was located antiparallel in the 
RASĀYAN J. Chem.

Vol. 14 | No. 3 |1790-1794| July - September | 2021

binding pocket at residues 411-413. The presence of hydrogen bond interaction between ricin-A and Arg413 indicates that ricin-A can break the salt bridge between aspartate residue with Arg413, thus, indicates that ricin- $\mathrm{A}$ is capable of entering the binding site of caspase- 8 . Because ricin- $\mathrm{A}$ is a large protein (267AA-32kDa), this docking simulation also proves that there is a part of ricin-A which binds to Val410, a residue located in pocket $S_{2}$ of caspase- 8 .

According to Huber and Hardy (2012) in Dagbay et al., 2014, each caspase protein might have a binding capacity on metal for its specific inhibitory characteristics, whereas caspase 9 binds two zinc ions. The binding of zinc in the active site of caspase-9 is the main characteristic of inhibition which in residue Cys230, His224, Cys272, His237, Cys239, and Cys287. ${ }^{20}$ Meanwhile, by following Raina et al., 2005 in Parrish et al., 2013, activation of caspase-9 as the initiator apoptosis through a phosphorylation reaction, occurs on a specific residue, Tyr153. ${ }^{21}$

The docking result of ricin-A and caspase- 9 does not show its binding to all residues mentioned above, it might be possible that activation of caspase- 9 by ricin-A occurs on an allosteric site of caspase- 9 . Furthermore, there is a lack of information about important amino acid residues in the binding pocket of ATG5 (Table-1).

Table-1: The Binding Mode and Scoring of Ricin-A in caspase-3, $-8,-9$, and ATG5

\begin{tabular}{|c|c|c|c|}
\hline $\begin{array}{l}\text { Name of Target } \\
\text { Protein }\end{array}$ & $\begin{array}{c}\text { Scoring } \\
(\mathrm{kcal} / \mathrm{mol})\end{array}$ & Hydrogen Bond & Hydrophobic Interaction \\
\hline Caspase-3 & -1030.4 & $\begin{array}{l}\text { Ser65A, His121A, Ser205B*, } \\
\text { Arg207B*, Asn208B, Ser209B* }\end{array}$ & $\begin{array}{c}\text { Cys163B, Ser205B, } \\
\text { Trp206B*, Ser249B, } \\
\text { Phe256B* }\end{array}$ \\
\hline Caspase-8 & -930.2 & Val410B* Ser411B, Arg413B* & not detected \\
\hline Caspase-9 & -935.0 & $\begin{array}{c}\text { Asp150B, Ser242B, His243B, } \\
\text { Gln245B, Ser382B, Asn389B, } \\
\text { Ser392B, Ile403B, Ser405B, } \\
\text { Arg408B, Lys410B }\end{array}$ & not detected \\
\hline ATG5 & -854.6 & $\begin{array}{c}\text { Asp395B, Ala397B, Asp398B, } \\
\text { Leu400B, Gly402B, Ala404B, } \\
\text { Asn408B, Cys409B, Val410B, } \\
\text { Ser411B, Arg413B, Thr419B, } \\
\text { Gln 423B, Arg430B, Tyr448B, } \\
\text { Lys461B, Arg471B, Lys473B, } \\
\text { Pro477B, Asp479B }\end{array}$ & not detected \\
\hline
\end{tabular}

*denotes similar binding mode with the protein substrate:

Ac-DEVD-AFC for caspase-3 $3 ; 19$

\section{CONCLUSION}

Ricin-A might be able to activate the caspases, particularly caspase- 3 and caspase- 8 . However, the interaction of ricin-A with caspase-9 and ATG5, although reveals several prospective bindings, is not with the specific essential amino acid residues in the catalytic reaction. Ricin-A induces apoptosis and inhibits autophagy. This study might contribute a molecular insight into understanding the anticancer activity of ricin-A.

\section{ACKNOWLEDGEMENT}

The authors would like to thank the Rector of Universitas Padjadjaran (West Java, Indonesia) for funding the publication fee via the Directorate of Research and Community Engagement. The present work was conducted in the framework of the doctoral dissertation of the first author at the Faculty of Pharmacy, Padjadjaran University, West Java, Indonesia. 


\section{RASĀYAN J. Chem.}

Vol. 14 | No. 3 |1790-1794| July - September | 2021

\section{REFERENCES}

1. M. Ahmed, A. M. Kabel, A. A. Adwas, A. A. Elkhoely, M. N. Abdel-Rahman and A. A. Eissa, Journal of Cancer Research and Treatment, 4, 4(2016), https://doi.org/10.12691/jcrt-4-4-3

2. J. C. Reed, American Journal of Pathology, 157, 5(2000), https://doi.org/10.1016/S00029440(10)64779-7

3. S. Megantara, M. Mutakin, E. Halimah, E. Febrina and J. Levita, Rasayan Journal of Chemistry, 13, 3(2020), http://dx.doi.org/10.31788/RJC.2020.1335766

4. M. Poręba, A. Stróżyk, G. S. Salvesen and M. Drąg, Cold Spring Harbor Perspectives in Biology, 5, 8(2013), https://doi.org/10.1101/cshperspect.a008680

5. K. McLuskey and J. C. Mottram, Biochemical Journal, 466, Pt2(2015), https://doi.org/10.1042/BJ20141324

6. J. Lim, Y. Lee, H. W. Kim, I. J. Rhyu, M. S. Oh, M. B. H. Youdim, Z. Yue and Y. J. Oh, The Journal of Biological Chemistry, 28, 28(2012), https://doi.org/10.1074/jbc.M112.364281

7. E. Y. Liu and K. M. Ryan, Journal of Cell Science, 125, (2012), https://doi.org/10.1242/jcs.093708

8. P. K. Panda, B. Behera, B. R. Mehar, D. N. Das, S. Mukhopadhyay, Sinha, P. P. Naik, B. Roy, J. Das, S. Paul, T. K. Maiti, R. Agarwal and S. K. Bhutia, Molecular Carcinogenesis, 56, 2(2016), https://doi.org/10.1002/mc22502

9. F. Zhu, Y. K. Zhou, Z. L. Ji and X. R. Chen, Frontiers in Plant Sciences, 9,(2018), https://doi.org/10.3389/fpls.2018.00146

10. S. Olsnes, Toxicon, 44, 4(2004), https://doi.org/10.1016/j.toxicon.2004.05.003

11. N. Sowa-Rogozińska, H. Sominka, J. Nowakowska-Gołacka, K. Sandvig and M. SłomińskaWojewódzka, Toxins (Basel), 11, 6(2019), https://doi.org/10.3390/toxins11060350

12. P. V. Rao, R. Jayaraj, A. S. Bhaskar, O. Kumar, R. Bhattacharya, P. Saxena, P. K. Dash and R. Vijayaraghavan, Biochemical Pharmacology, 69, 5(2005), https://doi.org/10.1016/j.bcp.2004.11.010

13. A. E. Jetzt, J. Cheng, E. Nilgun, N. E. Tumer and W. S. Cohick, The International Journal of Biochemistry and Cell Biology, 41, 12(2009), https://doi.org/10.1016/j.biocel.2009.08.007

14. P. G. Wahome, S. Ahlawat and S. J. Mantis, PLOS ONE, 7, 11(2012), https://doi.org/10.1371/journal.pone.0049075

15. E. Rutenber, B. J. Katzin, S. Ernst, E. J. Collins, D. Misna, M.P. Ready and J. D. Robertus, Proteins, 10, (1991), https://doi.org/10.1002/prot.340100308

16. S. Megantara, J. Levita, S. Ibrahim and B. P. Nguyen, Rasayan Journal of Chemistry, 14(1), 241(2021), https://doi.org/10.31788/RJC.2021.1416070

17. D. Kozakov, D. R. Hall, B. Xia, K. A. Porter, D. Padhorny, C. Yueh, D. Beglov and S. Vajda, Nature Protocols, 12, 2(2017), https://doi.org/10.1038/nprot.2016.169

18. S. Vajda, C. Yueh, D. Beglov, T. Bohnuud, S. E. Mottarella, B. Xia, D. R. Hall and D. Kozakov, Structure, Function, and Bioinformatics, 85, 3(2017), https://doi.org/10.1002/prot.25219

19. W. Watt, K. A. Koeplinger, A. M. Mildner, R. L. Henrikson, A. G. Tomaselli and K. D. Watenpaugh, Structure, 7, 9(1999), https://doi.org/10.1016/S0969-2126(99)80180-4

20. K. Dagbay, S. J. Eron, B. P. Serrano, E. M. Velazquez-Delgado, Y. Zhao, D. Lin, S. Vaidya and J. A. Hardy, Methods in Enzymology, 544, 9(2014), https://doi.org/10.1016/B978-0-12-417158-9.00009-1

21. A. B. Parrish, C. D. Freel and S. Kornbluth, Cold Spring Harbor Perspectives in Biology, 5, (2013). https://doi.org/10.1101/cshperspect.a008672

[RJC-6298/2021] 